\title{
Viagens, tremores e conchas: aspectos da natureza da América em escritos de José Bonifácio de Andrada e Silva, José Hipólito Unanúe e Dámaso Antonio Larrañaga Travels, quakes and shells: aspects of Nature in America in José Bonifácio de Andrada e Silva, José Hipólito Unanúe, and Dámaso Antonio Larrañaga’s papers
}

Resumo: Este artigo apresenta aspectos da produção científica de três ilustrados que atuaram na América do Sul: José Bonifácio de Andrada e Silva (1763-1838), José Hipólito Unanúe (1755-1833) e Dámaso Antonio Larrañaga (1771-1848). Os três naturalistas - de trajetórias, territórios e crenças diferenciadas - construíram suas versões sobre aspectos da natureza da América. Em comum, contribuíram com seus trabalhos científicos para a construção da geohistória americana. Foram escolhidos para análise por critérios de dispersão territorial e por suas diferentes abordagens sobre aspectos específicos das Ciências da Terra - temas que ainda hoje têm merecido menor atenção, mesmo entre os historiadores latinoamericanos das ciências. Este artigo argumenta que estes personagens não só construíram seus próprios conhecimentos sobre temperamentos (climas) e territórios, como também utilizaram seu conhecimento científico no implemento de ações políticas para os seus respectivos países em conformação.

Palavras-chave: História das Ciências. História da América Latina. Mineralogia. Terremotos. Geohistória.

Abstract: The paper presents aspects of the scientific production of three ilustrados who worked in South America: José Bonifácio de Andrada e Silva (1763-1838), José Hipólito Unanúe (1755-1833), and Dámaso Antonio Larrañaga (1771-1848). These naturalists, whose trajectories, territories and beliefs were different, built their particular version of Nature in America and contributed with their scientific work to the construction of American geohistory. They were chosen in this research by criteria of territorial dispersion and by different approaches about specific aspects of Earth Sciences - themes that up to now have not received full attention among Latin-American historians of sciences. This paper contends that these personalities built their own knowledge about 'temperament' (climate) and territories, and also used their scientific knowledge to implement political agenda for their respectives countries that were being conformed.

Keywords: History of Sciences. Latin America History. Mineralogy. Earthquakes. Geohistory.

Universidade de Évora. Centro de Estudos de História e Filosofia da Ciência. Évora, Portugal (mmlopes@uevora.pt).

". Museu de Astronomia e Ciências Afins. Rio de Janeiro, Rio de Janeiro, Brasil (alex@mast.br).

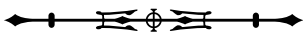




\section{A AFIRMAÇÃO DE UMA NATUREZA}

A natureza da América, desde o início do processo de conquista no século XVI, passou a ser objeto de constantes reflexões e juízos por parte dos pensadores europeus. Contudo, foi no último terço do século XVIII que as 'polêmicas do Novo Mundo' ganharam maior repercussão, no contexto das teorias de inferioridade, de imaturidade e degeneração da natureza americana'. Na base dessas discussões, que implicaram desdobramentos que acentuaram a relevância das questões políticas frente às científicas, estivera a obra de Georges-Louis Leclerc, Conde de Buffon (1707-1788). Amplamente referenciadas, tais polêmicas foram, de modo geral, relacionadas ao período dos movimentos de independência e afirmação política na América. Tratava-se de buscar os cânones pelos quais o continente americano poderia ser inserido na história ocidental.

A literatura latino-americana também já ressaltou que a obra referencial de Antonello Gerbi (1996), traduzida para o português como "O Novo Mundo: história de uma polêmica" - sem o termo "disputa" do original -, conferiu maior atenção aos debates realizados entre eruditos europeus. É certo que Gerbi acompanha as críticas feitas a esses eruditos, particularmente dos jesuítas expulsos, mas, na verdade, a disputa não foi efetivamente estabelecida entre eruditos 'americanos' e 'europeus'.

A disputa europeia pouco incorporou os argumentos de defesa da natureza americana, porque simplesmente não foram lidos os inúmeros escritos dos naturalistas e filósofos que, da América, com conhecimento de causa e experiência local, afirmaram a prodigalidade da natureza desse continente (Achim, 2008). De fato, muitos naturalistas que, de alguma forma, se vincularam à América contestaram aquelas teses, mas outros não viram necessidade de referir-se a elas para afirmar e reafirmar as potencialidades e as características dos territórios de que se ocupavam. Ou o fizeram de modo secundário em seus textos. Seus principais argumentos em prol das potencialidades da natureza americana, das condições favoráveis de vida e da importância dos seus próprios estudos eram retirados de práticas científicas específicas, de estudos realizados na Europa, de trabalhos de campo e de suas culturas ilustradas.

Nesse artigo, são considerados trechos dos textos de José Bonifácio de Andrada e Silva (1763-1838) em coautoria com seu irmão Martim Francisco Ribeiro de Andrada (17751844); de José Hipólito Unanúe (1755-1833); e de Dámaso Antonio Larrañaga (1771-1848). Esses autores pouco criticaram, e não de forma defensiva, textos clássicos. Criaram suas próprias teorias e identidades científicas locais, regionais, e tiveram em comum a afirmação - por meio de práticas científicas específicas - das possibilidades da natureza americana para o implemento de ações políticas para os respectivos países em conformação.

O primeiro texto é um dos últimos estudos cientíícos de José Bonifácio de Andrada e Silva, intitulado "Viagem Mineralógica na Província de São Paulo", realizada em 1820, em companhia do irmão, Martim Francisco, o Diretor Geral das Minas de Ouro, Prata e Ferro da Capitania de São Paulo. O segundo, escrito em 1806, e em segunda edição em 1814, intitulado "Observaciones Sobre el Clima de Lima y su Influencia en los Seres Organizados, en Especial en el Hombre", é de autoria do peruano José Hipólito Unanúe. O terceiro, intitulado "Memoria geológica sobre la reciente

\footnotetext{
1 Embora influentes, essas teorias evidentemente não foram uma unanimidade. Entre os autores mais mencionados que se referiram à polêmica, dois anos após o livro de Cornelius de Pauw (1739-1799) - "Recherches philosophiques sur les Américains", ou "Mémoires intéressants pour servir à l'Histoire de l'Espèce Humaine. Avec une Dissertation sur l'Amérique \& les Américains", de 1771 - o abade Guillaume-Thomas-François Raynal (1713-1796) publicou a "História Filosófica e Política dos Estabelecimentos e do Comércio dos Europeus e das Duas Índias”. O debate foi revigorado entre 1777 e 1780, quando o escocês William Robertson (1721-1793) publicou seus diversos volumes sobre "The History of America". Para descrever o quadro físico, climático e antropológico da América, o reitor da Universidade de Edimburgo apoiou-se nos autores mencionados, nos cronistas da conquista e nos viajantes ilustrados. Também para ele, no novo continente predominava o frio, o ar maligno, as espécies animais eram degeneradas, a população indígena era selvagem. Para uma revisão dessa literatura, ver Arregui (1994), Gerbi (1996) e Fonseca (1997).
}

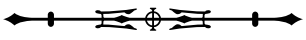


formación del Río de la Plata, deducida de sus conchas fósiles", escrito em Montevidéu por volta de 1819, é de Don Dámaso Antonio Larrañaga.

\section{VIAGENS PAULISTAS}

José Bonifácio de Andrada e Silva dispensaria apresentação aos leitores brasileiros. Cabe lembrar, em termos de sua trajetória, que recebeu o título de Bacharel em Filosofia e Leis pela Universidade reformada de Coimbra, onde fora estudar desde 1780, em companhia dos irmãos Martim Francisco e Antônio Carlos. Como diversos outros membros das elites coloniais - seu pai possuía a segunda maior fortuna de Santos -, os Andrada juntaramse às elites cultas da metrópole e Bonifácio integrou o grupo de naturalistas da Academia Real das Ciências de Lisboa, liderado por seu professor, Domenico Vandelli, dedicado ao estudo das produções naturais da colônia e do Reino (Munteal Filho, 1993, 1998). Complementou sua formação de 'metalurgista de profissão' visitando as principais escolas de mineração europeias e importantes regiões mineiras, mantendo contato com expoentes da ciência mineralógica. São dessa fase suas classificações de novos minerais. Ao retornar à Portugal, Bonifácio foi arregimentado por D. Rodrigo de Souza Coutinho, ministro da Marinha e do Ultramar, para assumir postos importantes no âmbito da administração central do Império português, para a aplicação firme e eficiente da sua política reformista (Lyra, 1994; Cardoso, 2001).

Bonifácio, a convite de D. Rodrigo, foi nomeado Intendente Geral das Minas e Metais do Reino de Portugal por Carta Régia de 18 de maio de 1801. D. Rodrigo, ao contrário de outros estadistas e eruditos portugueses que afirmavam, à época, ter sido a mineração a razão da decadência de Portugal, defendia a recuperação da produção mineral, sobretudo de ouro, como atividade chave para a regeneração do Reino (Silva, 2004). Além de promover a repressão ao contrabando e aos 'descaminhos', ele insistiu na política de que o resgate da mineração só seria possível tendo por base a aplicação das ciências a ela relacionadas, como a mineralogia, montanística e metalurgia, o aprimoramento técnico e a melhor instrução dos mineiros.

No cumprimento dessa políica, foram aprovados um novo regimento para o funcionamento das minas e estabelecimentos metálicos do Reino, novas definições de competência do Intendente e a sua respectiva área de atuação, e estabelecido o princípio do monopólio da exploração mineira em favor do Estado. Ao Intendente foram concedidos os mais amplos poderes administrativos e técnico-científicos. Além desse posto, Bonifácio acumulou outros cargos, como o de Superintendente do Rio Mondego e Obras Públicas da Cidade de Coimbra (Alvará de 13/07/1807), de Desembargador da Relação do Porto (Carta de 08/08/1806), Lente da Cadeira de Metalurgia da Universidade de Coimbra (Carta Régia de 15/04/1801), Diretor do Curso Docimástico da Casa da Moeda de Lisboa (Decreto de 12/11/1801), Primeiro Secretário da Academia Real das Ciências de Lisboa. Longe da anterior interpretação do 'acúmulo de cargos burocráticos', Bonifácio, nessas posições de poder e prestígio, esquadrinhou o Reino a serviço da Intendência, transformando-a em seu laboratório de pesquisas, sendo dessa fase de atividades sua vasta produção científica (Varela, 2006b).

Tendo permanecido trinta e seis anos em Portugal, no ano de 1819, José Bonifácio recebeu autorização do governo para retornar ao 'Reino do Brasil'. A literatura recente já se posicionou contra um certo tipo de historiografia de viés nacionalista, que insiste em identificar como brasileiros ou portugueses aqueles leais e eruditos súditos, que, a exemplo do "português d'Andrada" - "o mais humilde e fiel súdito português" (Lopes, 1990), se dispuseram a aceitar cargos de direção, a esquadrinhar o Reino e o Ultramar, a ser útil ao governo. José Bonifácio, o naturalista português natural do Brasil,

\footnotetext{
2 As reflexões aqui presentes sobre José Bonifácio de Andrada e Silva estão baseadas em Varela (2006b, 2009).
}

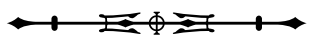


trabalhou intensamente para a institucionalização das ciências naturais em Portugal e depois no Brasil, sempre a serviço da Coroa e atraído pela ideia de construção de um império luso-brasileiro. Em suas memórias científicas que perpassam as questões econômicas e políticas, não há qualquer referência às ideias de independência ou separação da colônia (Varela, 2009).

No quadro de grandes mudanças na vida econômica, política e social do já Reino do Brasil, unido a Portugal e Algarves, foi dada continuidade à política de D. Rodrigo de Sousa Coutinho, o qual considerava que a estada na América não era uma solução temporária para a resolução dos problemas europeus de Portugal. Agora em Santos, Bonifácio também continuou sua prática político-científica, começando de imediato a se imiscuir nas mais variadas atividades. Em 23 de março de 1820, partiu de Santos, na companhia do irmão, para sua viagem mineralógica pela Província de São Paulo. Passando pela capital e atingindo, como ponto mais distante, Piracicaba, os naturalistas, em um trajeto que já teve também seu caráter estratégicopolítico assinalado, seguiram o curso do rio Tietê, procedendo conforme a tradição dos bandeirantes em suas expedições de reconhecimento e exploração dos 'sertões' (Kok, 2004).

A "Viagem Mineralógica" difere qualitativamente dos demais textos de Martim Francisco, inclusive dos seus próprios relatos de viagens anteriores à mesma região (Varela e Lopes, 2007), evidenciando, em diversos detalhes, a contribuição autoral decisiva de Bonifácio. $\mathrm{Na}$ "Viagem Mineralógica" não faltam as exaltações à pródiga natureza paulista. A província possuía uma "vista magnífica", com "bonitos vales, largos e extensos", ribeiros de água cristalina, animais "belos e robustos", montes cobertos pelos mais ricos minerais, em muitos dos quais afirmaram encontrar-se ouro. A estrada de São Roque era cercada de capoeiras e matas, cuja vegetação variada mostrava-se "rica e prodigiosa". Muitas daquelas árvores, por causa das suas magníicas flores, podiam figurar nos jardins e parques, principalmente uma, que parecia ser "da espécie dos plátanos, e outra, cujas folhas, antes de cair, se faziam umas vermelhas, outras amarelas" (Silva e Andrada apud Falcão, 1963, I, p. 533). Tratava-se, portanto, de uma região extremamente bela e encantadora, que provocava sensações e sentimentos de êxtase por ser uma natureza rica, na visão do metalurgista de profissão, mas que também deveria ser olhada com mais cuidado em função das inúmeras produções naturais que possuía e das utilidades que poderia oferecer. Distante de qualquer natureza hostil ou clima insalubre, caberia aos homens de ciência estudar profundamente essa natureza pródiga para descobrir as suas potencialidades, seus recursos naturais que ajudariam a Coroa portuguesa a promover a modernização econômica de todo o império.

Embora faltassem construções das antigas civilizações do então território paulista, a magnitude do primeiro salto do rio Assungui, sua beleza encantadora, deixou o naturalista perplexo: "Este salto minimamente me deleitou num país totalmente falto de belezas d'arte, e porque a um homem tão batido de trabalhos são precisos grandes esforços da natureza para o arrebatarem" (Silva e Andrada apud Falcão, 1963, I, p. 185).

Mesmo aos olhos do metalurgista, o espetáculo magnífico da natureza não era um objeto confinado apenas ao estudo científico. Espaço reservado para as sensações positivas ou negativas, pode-se interpretar nessas menções indícios que apontam para a presença de temas relacionados às sensibilidades românticas na memória do naturalista (Naxara, 2009). Mas a visão de natureza que predomina em seus trabalhos está relacionada às ideias da utilidade da natureza, de tradição baconiana, da "economia da natureza", de Lineu, estudada e seguida desde Coimbra. Para Bonifácio, o mundo natural, como espaço de pesquisa científica, deveria ser racionalmente explorado pelo homem, e a ciência seria o instrumento que teria o papel de facilitar a exploração dessa natureza intocada.

A riqueza da natureza mineral da província foi sempre o destaque de Bonifácio. Os locais em que havia minas, sobretudo de ferro, a possibilidade de fundição do 
metal e a instalação de fábricas foram cuidadosamente mapeados e assinalados. Na avaliação de Bonifácio, os terrenos intemperizados da vila de Parnaíba eram o centro de um "vasto distrito aurífero", o que tornava a vila local bastante próprio para o estabelecimento de um "centro metalúrgico e uma administração geral”. Além de ouro, poderiam ser extraídos "abundantes minerais de ferro hematítico, vermelho e branco, excelente ferro magnético da rica mina de Pirapora, e era provável que entre os muitos veios quartzosos, que cortavam os seus contornos, se achassem alguns que encerravam metais úteis" (Silva e Andrada apud Falcão, 1963, I, p. 514).

Deixando a vila de Parnaíba, os naturalistas seguiram em direção a Pirapora e Boturuna. Em Pirapora, foram extremamente felizes ao encontrar pedaços de "excelente mineral de ferro cor de sangue de boi, e vermelho, que pousa sobre banco de grés", como também um "cume todo formado de mineral de ferro magnético, espesso e pesado, que está às vezes coberto de ocre de ferro vermelho, com as cavidades cheias de manganês negra e escamosa" (Silva e Andrada apud Falcão, 1963, I,, p. 515). Crostas de material ferruginoso e de alteração intempérica excitaram a imaginação de Bonifácio, levando-o a pensar na possibilidade de estabelecer fundições no local, uma vez que havia ali em abundância "xisto argiloso e hornblendico" (sic), boa pedra calcária, "grossa e cinzenta", que se alternava com o "xisto argiloso". E para combustível havia um bom número de madeiras de lenha.

O naturalista não se preocupou apenas em descrever e exaltar a natureza da província, mas também em preservá-la, sublinhando a falta de cuidado dos habitantes da região com relação às matas e bosques. Como exemplo da destruição dos arvoredos, os naturalistas relataram que, saindo de um engenho próximo à região de Jundiuvira, sentiram a falta de bosques. Bonifácio afirmou que as antigas matas haviam sido todas destruídas "barbaramente com o fogo e machado". Se o governo não tomasse medidas enérgicas contra aquela "raiva de destruição", acabariam as madeiras e lenhas; os engenhos seriam abandonados, as fazendas se esterilizariam, a população emigraria para outros lugares, a civilização atrasar-se-ia, e a administração da justiça, e a punição dos crimes cada vez experimentaria maiores dificuldades no meio dos desertos (Silva e Andrada apud Falcão, 1963, I, p. 523).

Expressamente utilitária, sua preocupação com a conservação dos bosques e arvoredos relacionava-se a uma perspectiva de contribuir para que o 'Reino do Brasil' aproveitasse melhor as suas riquezas naturais. Das árvores e matas provinham a madeira e a lenha, fontes importantes de combustível para o funcionamento dos fornos das fundições de ferro e de chumbo. Daí, o sentido preservacionista de Bonifácio.

O "miserável estado" dos rios, como Tamandataí (hoje, Tamanduateí) e Tietê, causado pela destruição dos seus leitos pela ação humana, também chamava sua atenção:

\begin{abstract}
Sem margens, sem leitos fixos, sangrados em toda a parte por sarjetas, que formam lagos e pauis que inundam esta bela planície; e o que é mais para lastimar, é que quase todos estes males não são obra da natureza, mas sim o resultado da ignorância dos que quiseram melhorar o curso destes rios (Silva e Andrada apud Falcão, 1963, I, p. 507).
\end{abstract}

"A viagem Mineralógica pela província de São Paulo" possibilitou ao naturalista uma ideia perfeita da "fertilidade e riqueza do seu território" e é marcada por um conjunto de propostas de ações prospectivas. Não só a natureza era pródiga, os indícios de recursos minerais prometedores, o clima favorável, como também seus habitantes empreendedores se melhor incentivados e as mulheres, como as da vila de Sorocaba, "verdadeiro tipo ou modelo de beleza: regularidade nas suas feições, uma boa figura, e esbelta estatura, cor de jasmins e rosas, e amabilidade e bondade de caráter" (Silva e Andrada apud Falcão, 1963, p. 530).

A constatação da riqueza natural da capitania deixava transparecer um otimismo típico dos homens da llustração quanto ao futuro da região, uma vez que poderia constituir- 
se em fonte de bem estar material para a sociedade, gerar lucros ao Estado e trazer a felicidade pública. No parágrafo final do relato da viagem não faltam os prognósticos em relação ao futuro de São Paulo, as expressões de afirmação do potencial da natureza como a principal fonte de civilização e a capacidade de liderança dos habitantes da região em relação às demais que compunham o 'Reino do Brasil':

Sendo povoada e civilizada, formará um grande Estado, visto que pela variedade do seu clima, sendo parte entre os trópicos, a outra, fora deles; pela abundância de madeiras, e dos seus campos, pelos inumeráveis rios e ribeiros, em grande parte navegáveis, pelas riquezas de ferro, ouro, diamantes, outros metais, e pedras preciosas, é realmente um dos países mais privilegiados do globo, e uma obra prima de benfazeja natureza. Acrescente-se, que a raça branca, que o habita, é das mais belas, e fortes da América meridional. Foi a ela, e aos índios conquistados pelos paulistas, que é devida a descoberta e a povoação dos vastos desertos do Brasil. Aos paulistas se devem os primeiros habitantes do Rio de Janeiro, Minas Gerais, Goiás, Cuiabá, Mato Grosso, Santa Catarina e Rio Grande do Sul (Silva e Andrada apud Falcão, 1963, I, p. 535-536).

\section{TEMPERAMENTOS E TREMORES}

En el centro de este feliz pedazo del globo está el valle ameno de Lima, sítio de la rica y culta capital del Perú. Así parece que alrededor de ella sobresalen las gracias y los encantos de la agradable temperatura de esta costa... todos los viajeros de Europa convienen en ser el del Paraíso, el temperamento de Lima (Unanúe, 1975, p. 14).

Exaltações à natureza de Lima, apoiadas em observações contínuas, instrumentos de medidas e dados estatísticos também marcam a obra "Observaciones sobre el clima de Lima y sus influencias en los seres organizados en especial el hombre". Na rica e culta Lima, de clima ameno, o otimismo ilustrado já não necessitava esperar o futuro, como em São Paulo. Em 2 de abril de 1814, José Hipólito Unanúe assinava a 'advertência' à segunda edição das "Observaciones...", publicada pela primeira vez em 1806. Nela, fez constar o apreço com que a edição anterior havia sido recebida não só pelos literatos da América, como também pelos da Europa, e transcreveu os comentários elogiosos publicados no "Memorial Literário", de Madrid, em 20 de maio de 1808, n’. 14. O Memorial não duvidava em afirmar que este era um dos melhores tratados sobre o tema já publicado. Anunciando a próxima publicação de mais uma seção, destacava a erudição do autor e - para orgulho dos peruanos - considerava estranho que "llevando nosotros a los peruanos muchos siglos adelantados en la ilustración y bastantes años en la erección de Cátedras de todas clases, se haya publicado el primer libro de esta clase en Lima y no en Madrid" (Unanúe, 1975, p. 6).

À essa época, Unanúe já era uma autoridade reconhecida em matéria de ciências e medicina. Sua trajetória conta com uma ampla literatura, que o caracterizou como um "amante do país" (Porras Barrenechea, 1974) na busca, por meio das ciências, de conhecimento sobre todos os aspectos físicos, históricos e sociais do Peru. Ao contrário de diversos estudiosos de outras regiões da América hispânica, como Francisco José de Caldas, por exemplo, que, como agitador político, lutou pelo rompimento dos laços entre a metrópole e a colônia (Fonseca, 1994), Unanúe - também como Bonifácio - não foi um súdito rebelde. Seu prestígio entre as elites peruanas, enquanto conselheiro de vice-reis, não o impediria de, proclamada a Independência, também como Bonifácio, participar ativamente da construção do novo país que se organizava, atuar como ministro e se destacar na representação por Puno no Congresso Constituinte que elaborou o projeto de Constituição da República peruana (Varela, 2006a; Casalino, 2008).

Nascido em Arica, em uma família de status social elevado, como a de José Bonifácio, Hipólito Unanúe recebeu a instrução primária de caráter estritamente religioso na própria família, continuada no Seminário de San Jerônimo, em função de seus interesses eclesiásticos. Abandonando a vocação religiosa para dedicar-se ao estudo das ciências, Unanúe obteve o grau de doutor em Medicina pela Real y Pontifícia Universidad de San Marcos, em Lima, em 1783. Na Cátedra de Anatomia da Universidade de 
San Marcos desde 1787, Unanúe construiu seu espaço de crítica à escolástica e de difusão dos princípios da observação e da experimentação enquanto procedimentos centrais para a prática científica. Responsável pela fundação do Anfiteatro Anatômico (1792) e pela criação da Escola de Medicina de San Fernando (1811), além de contribuir para o processo de institucionalização das ciências médicas no Vice-Reino, Unanúe reuniu os estudiosos na Sociedade Amantes del País; fundou a revista de difusão das ciências e letras "La Casa de los Sábios"; publicou diversos artigos no periódico "Mercurio Peruano"; e foi sócio de diversas academias científicas, como a Real Academia de Ciências Naturais e Medicina de Madrid, a Sociedade de Ciências da Baviera, a Sociedade Lineana de Paris e a Sociedade de Filosofia da Filadélfia (Saladino García, 1996).

A obra de Unanúe já foi interpretada por diversos autores. Para uns, a natureza do vice-reino do Peru, exaltada e dignificada por Unanúe, tornou-se um espaço para a afirmação patriótica (Cañizares-Esguerra, 1997). Unanúe teria enfatizado a ideia de que a natureza local era um microcosmo que poderia fornecer todos os recursos ao mundo inteiro, dando destaque a alguns produtos específicos da região, como a coca e a quina. Em sua discussão sobre a "Influencia del clima sobre los animales", na qual deixa seus leitores saberem das repercussões internacionais de sua obra pela tradução de seus parágrafos em Archibaldo Smith, "Peru as it is", suas críticas a Buffon são explícitas. Sistematiza quatro das proposições de Buffon sobre os animais da América: os animais comuns ao antigo e novo continente seriam mais corpulentos no primeiro; os animais indígenas do novo hemisfério são menores do que os do antigo; as espécies de animais domésticos europeus degeneraram na América; e poucas são as famílias peculiares dessa parte da Terra. Unanúe, recorrendo à autoridade do presidente Jefferson ("Notes on State of Virginia"), considera suas tabelas comparativas dos animais existentes nos dois continentes suficientes para comprovar a falsidade das teses buffonianas. Mais do que isso, Unanúe partilhou a ideia de que foi um desígnio da providência a diversidade de plantas e animais nas diferentes regiões das Américas. A defesa do clima americano tornou-se um tema dominante no pensamento médico peruano próximo ao período da independência, permitindo, assim, a elaboração de uma matéria médica distintamente americana (Glick, 1991).

As "Observaciones sobre el clima de Lima..." inseriram-se no quadro variado das teorias neo-hipocráticas revigoradas desde meados do século XVIII. Estas, cada vez mais fazendo uso dos novos instrumentos científicos de medição, introduziram concepções mecanicistas para análise da influência dos fatores ambientais sobre os seres vivos, afastando-se de interpretações puramente qualitativas sobre a natureza (Salaverry, 2005; Achim, 2008). Assim, a "Historia del clima", a primeira seção do manual de Unanúe, segue os cânones dessas tradições, situando 'a mais célebre e rica' cidade da América meridional nos seus parâmetros quantificados de latitudes, disposição espacial entre os Andes e o Pacífico, as qualidades do solo, das águas, da atmosfera, as influências do Sol e das estações do ano, as influências da Lua, a influência dos eclipses. Com o subtítulo em destaque "METEOROS", após descrever os ventos, dissertar sobre as causas de não chover e apenas garoar em Lima, tratar dos trovões e raios, Unanúe passa a descrever no subcapítulo XI os "Temblores".

Associados, no quadro das teorias neo-hipocráticas, às estações do ano, os tremores no Peru ocorriam preferencialmente entre a primavera e o estio, podendo ocorrer também no outono, no 'Veranito de San Juan'. Os dias 'mais vários' eram os mais expostos a tremores. Suas horas eram as da noite, que os antigos identificavam justamente ao outono e à primavera: duas ou três horas após o pôr do Sol, ao apagar-se a 'luz zodiacal', e mais usualmente em torno da aurora. A frequência dos pequenos tremores na primavera, explicava Unanúe, era um indício de que as entranhas da terra se descarregavam por partes e que, portanto, não seria necessário temer a ocorrência de terremotos. Mas se os tremores viessem uns sobre os outros, a curtos intervalos, isto significava um incêndio sucessivo e por partes de uma grande quantidade 
de material, devendo se recear então que "abrasándose el mayor depósito, siga um violento terremoto". As explicações de Unanúe para as causas naturais dos terremotos seriam ao tom de seu tempo, não aceitando mais explicações de caráter místico para os terremotos, embora não descarte que os antigos, os religiosos e mesmo os pagãos garantiam que os tremores de Lima se tornavam menos comuns e menos intensos à medida que ecoava dos templos o sagrado cântico do "Trisagio", pois só aquele a quem se consagrava o sublime cântico é que teria o poder de "conmover la tierra desde sus cimientos o mantenerla en reposo” (Unanúe, 1975, p. 40).

O tremor sentido em Lima em $1^{\circ}$ de dezembro de 1806, por não ter sido tão destruidor, como o que o precedera em 1746, acrescentava Unanúe, parecia ter atestado justamente a crença dos antigos. Os efeitos desse terremoto de 1746 seriam por diversas vezes retomados, particularmente quando dos relatos e das discussões sobre a tragédia resultante do terremoto de Lisboa de 1755. Em "Candide", Voltaire fez Pangloss afirmar que $o$ terremoto de Lisboa não se tratava de nenhuma novidade. Mencionando o terremoto de Lima, associando iguais causas a iguais efeitos, não tinha dúvidas sobre, e sustentava como algo devidamente demonstrado, a existência de uma corrente subterrânea de enxofre, desde Lima até Lisboa. Elie Bertrand (1713-1797), pastor da igreja francesa em Berna, amigo de Voltaire, autor de um dos mais influentes tratados sobre os terremotos de meados do século XVIII, que reunia as diversas teorias, dados sobre terremotos e eventos relacionados na Suíça, também fazia referências, seguindo Buffon, às teorias que supunham a existência de matérias inflamáveis, como enxofre, no interior da Terra (Carozzi, 1983; Bork, 1991).

Contudo, o terremoto de $1806 \mathrm{fez}$ mais do que confirmar a eficácia das orações. Confirmava também para Unanúe a direção preferencial dos tremores sul-norte, seguindo a cordilheira e "el clumplimiento del período o evolución semisecular" dos terremotos no Peru (Unanúe, 1975, p. 41). Os terremotos, para Unanúe, não eram fenômenos episódicos ou ocasionais, mas regulares. Sua experiência e os dados registrados em Arequipa, Lima e Quito desde 1582 evidenciavam uma periodicidade de meio século para os tremores mais violentos.

Nos registros de Unanúe, naquele dia, às seis da tarde, Lima estremeceu com violência por um minuto e meio. Às oito da noite, a maré subira no porto de Callao a 18 pés de Burgos, movimento que se repetiu com mais força às nove horas, embora às dez o mar já estivesse tranquilo. $\bigcirc$ movimento ondulatório do tremor podia ser sentido nas plantas dos pés, sob as quais, com rapidez, passavam as 'ondas ou ondulações da terra'. Tais movimentos de ondas já haviam sido estabelecidos como uma possível causa dos terremotos por John Michell (1724-1793), autor de uma das mais fundamentadas e difundidas explicações para o terremoto de Lisboa. Michell aceitava uma conexão entre terremotos e vulcões, cujas manifestações considerava episódicas, mas não relacionava mais terremotos com condições atmosféricas (Carozzi, 1983; Oldroyd et al., 2007), como Unanúe continuava fazendo.

Didaticamente, apresentando as diversas questões relacionadas às discussões sobre terremotos, vigentes desde a segunda metade do século XVIII, mas adotando ainda a perspectiva da influência climática, já em desuso, Unanúe explicou que os grandes terremotos eram precedidos (e também seguidos) de copiosas chuvas. Estas, encharcando a terra, penetravam, preenchiam suas cavidades e seguindo-se dias quentes, produziam enormes quantidades de vapores subterrâneos. Quando a terra não conseguia transpirá-los completamente, os vapores permaneciam sujeitos a serem incendiados pela excitação do fogo elétrico ou do que continham os vulcões, que atuavam com o aumento do calor da atmosfera. Ao incêndio provocado pelos terremotos, se seguiam uma maior expansão dos vapores, explosões violentas, rachaduras e 'transtorno da terra'.

Até o final do século XVIII, tais explicações de que os terremotos eram devidos a algum tipo de explosão no interior da Terra eram, de um modo geral, aceitas e suas causas estavam ainda em debate. A existência dos 
pirofiláceos, hidrofiláceos e aerofiláceos de Athanasius Kircher (1601/2-1680), que conectavam as cavidades no interior da Terra, permanecia amplamente difundida, e as convulsões de tais pirofiláceos estiveram na base das diversas explicações geradas pelo grande terremoto de Lisboa, em 1755. Diversos autores associavam a ocorrência de terremotos a descargas elétricas na atmosfera ou no interior da Terra. Buffon, por exemplo, considerava a existência de dois tipos de terremotos. Aqueles diretamente causados pelas explosões subterrâneas dos vulcanismos e aqueles de maior amplitude, resultantes da pressão dos vapores através dos condutos subterrâneos, causados por explosões, como ocorria nas minas de carvão. Águas percolando através de materiais como pirita poderiam também ser responsáveis nesses casos (Oldroyd et al., 2007).

Sem maiores referências, Unanúe registrou também, abaixo da tabela dos períodos dos grandes tremores, as datas das sucessivas explosões vulcânicas do Cotopaxi e Pichincha, em Quito, a partir de 1534, e do Quinistacas, em Arequipa, em 1600. E nas tabelas meteorológicas de Lima do ano de 1799, que encerravam essa seção das "Observaciones sobre el clima de Lima ...", vinham indicados mês a mês, dia a dia: as fases da Lua; o calor, medido pelos termômetros de azougue, com a escala de Réaumur (os termômetros de 'espírito de vinho' assinalavam um ou dois graus a mais no ápice do outono); o tempo, se brilhava o Sol, se nublado, a chuva grossa, a garoa, a garoa grossa quase como chuva; e os 'temblores', assinalados os dias e as horas em que ocorreram e seu grau de intensidade e de ruído.

A ideia de a cada cinquenta anos ser necessário reconstruir a capital do Peru the "atravessava de dor a alma". Além da população, a vegetação sofria enormemente nestas "épocas funestas". O grande terremoto de 1687 fora um golpe mortal para a agricultura peruana. Os campos tornaram-se infecundos para o trigo, e somente vinte anos depois começaram a se recuperar. A enfermidade sofrida pelo trigo teria sido um verdadeiro 'tizón' (um fungo parasita do trigo). Unanúe, com sua prática médica, utiliza essa experiência para, apoiado em outros autores, refletir sobre a possibilidade de buscar no interior da Terra 'os contágios originais', uma vez que as plantações do Peru, até então, não haviam padecido de tal enfermidade. Mesmo assim, Unanúe parecia compartilhar o otimismo ilustrado da época e anunciava que os tremores não se destinavam somente à desolação do globo:

Así, cuando pasan los soles dentro del otoño, un temblor cubre de vapores la atmósfera, para que empiece la mollizna propia de esta parte del año, y a los días muy opacos, fuera de tiempo, los aclara un temblor, sacudiendo los vapores de la atmósfera, y tal vez su frecuencia en primavera es para romper las muchas nieblas y vapores que nos rodean, y que sucedan con más facilidad los claros días de estío (Unanúe, 1975, p. 41).

Naquele "feliz pedaço do globo" que era Lima, os tremores ordenavam a constituição do seu clima paradisíaco.

\section{RIOS DE CONCHAS E OSSOS}

\begin{abstract}
Pero lo más extraño para aquellos sabios, lo más interesante para los Americanos del Sur, es haberse encontrado en aquellas diferentes formaciones muchos mamilares que solo tienen afinidad con los de América meridional, y en particular con los del Rio de la Plata. Nuestro Tapir o Anta, nuestra Didelphis o Comadreja, nuestros Myrmecophagas y Bradypos o perezosos y hormigueros y nuestras cavias y cuises, tienen también sus representantes en aquellas remotas partes del globo. Estas formaciones tienen también sus terrenos análogos en otros reinos de Europa. Mr. Webster leyó una muy interesante Memoria que se ha publicado en el $2^{\circ}$ volumen de las Transacciones de la Sociedad Geológica de Londres en que presenta igual serie de deformaciones en Inglaterra (Larrañaga, 1923b, p. 10).
\end{abstract}

Localmente situado em seu referencial de investigação, o padre Dámaso Antonio Larrañaga, em suas memórias, inverteu completamente e sem qualquer problema o sentido dos discursos dos tratados europeus sobre as afinidades entre os animais da América meridional e da Europa. Como outros naturalistas do Prata, dos territórios que conformariam o Brasil ou o Peru, "Larrañaga priorizava 
seu conhecimento de campo e valorizava as condições onde viviam a fauna, a flora e mais importante ainda, valorizava onde ele mesmo vivia" (Podgorny e Lopes, 2008, p. 49).

Com seu conhecimento de campo e com as publicações internacionais à disposição, uma vez que atuou como organizador das primeiras bibliotecas e museus nas regiões de Rio de la Plata e Banda Oriental, Larrañaga contestava Cuvier. O Megatherium de Cuvier do rio Lujan, tinha

en la boca solo molares, sus huesos cortos y muy
anchos, su testa ósea tan grande como un horno
de panadería: su cola cubierta de grandes escudas
que conservamos, indican de un modo indudable
que no puede ser sino un subgénero de nuestros
tatus; y nos permitirá que en este sentido lo
denominemos en adelante Megatherium cuvierii
(Larrañaga, 1923a, p. 23).

Larrañaga, que manteve contato e correspondência com diversos naturalistas europeus que visitaram as regiões de Rio de la Plata, no início do século XIX, como John Mawe, Aimé Bonpland, Friedrich Sellow e Auguste de Saint-Hilaire ${ }^{3}$, seria imortalizado por uma nota de Cuvier como "savant Brasilien", na segunda edição de suas "Recherches sur les Ossemens Fossiles" - uma referência à época em que os territórios da Banda Oriental permaneceram anexados ao Brasil.

A l'instant où l'on achève l'impression de cette section, M. Auguste de Saint-Hilaire, savant botaniste, qui vient de faire au Brésil le voyage le plus intéressant, et d'y rassembler les collections les plus riches, me communique l'extrait suivante de la lettre d'un savant Brasilien, qui annonce que le mégatherium auroit poussé son analogie avec les tatous jusqu'à être comme eux revêtu de cuirasses écailleuses. Nous devons attendre avec impatience le mémoire important que cette lettre nous promet. Extrait d'une lettre de D. Damasio Larrañaga, curé de Montevideo, à M. Auguste de Saint-Hilaire (Cuvier, 1823, p. 191).

Associando seu grande quadrúpede encouraçado, que Larrañaga não duvidava em classificar como Dasypus, ao Megatherium, "Larrañaga inaugurava um debate que só se encerraria vinte anos depois" (Podgorny, 2007).

Como Bonifácio e Unanúe, Larrañaga também dispensaria apresentação em seu próprio país, embora sua obra seja menos conhecida entre os historiadores latinoamericanos das ciências. De família com alguma posse, mas sem tradição senhorial como os demais, o naturalista nascido em Montevidéu, filho de pai imigrante e mãe portuguesa, estudara no Real Colégio de San Carlos, em Buenos Aires. Mais tarde, ocupou posições controvertidas, mas de destaque, no cenário político e religioso do Rio de la Plata. Consagrado no Rio de Janeiro, no Uruguai atingiu o posto mais alto da hierarquia eclesiástica, o de ProtoNotário Apostólico (Favaro, 1950). Já idoso e cego, foi presidente da comissão encarregada de organizar o Museu de Montevidéu, criado em 4 de setembro de 1837 (Lopes e Podgorny, 2000). Foi subdiretor da Biblioteca Pública de Buenos Aires entre 1813 e 1815, e ocupou o posto de senador quando da constituição da República uruguaia. Havia sido o diretor, no governo Artigas (com quem teria partilhado os estudos primários), da primeira Biblioteca Nacional do Uruguai, inaugurada em 25 de maio de 1816, destruída no ano seguinte pela ocupação luso-brasileira.

Estudiosos do período da dominação luso-brasileira da Banda Oriental criticaram severamente aqueles que, como Larrañaga, receberam e atuaram com o invasor. Outros julgaram que aqueles não teriam sido 'desgraciados cortesanos', mas patriotas que, por força das circunstâncias, teriam estrategicamente recebido a monarquia lusobrasileira convictos de que seria efêmera, como de fato o foi (Gonzáles, 1950). Larrañaga, que passou grande parte da vida reunindo coleções e classificando as amostras que recolhia em viagens, uniu em sua morte todas as facções em luta na prolongada guerra civil uruguaia. Sua obra científica tornou-se uma unanimidade. Sobre as proporções de seu trabalho, ele mesmo diria em seu discurso inaugural da Biblioteca de Montevidéu que:

\footnotetext{
3 "O sr Chapre, cunhado do sr. Cavailler, que aqui exerce a medicina, apresentou-me, esta tarde, ao padre Larrañaga..." (Saint-Hilaire, 2002, p. 188).
}

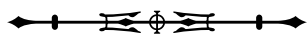


"Vuestro país abunda en producciones nuevas; y en este corto recinto, en medio de las mas serias ocupaciones de mi ministerio, he clasificado y descrito sistemáticamente mas de mil especies desconocidas en sus tres Reynos" (Larrañaga, 1924, p. 144). Suas obras e fragmentos de trabalhos, que permaneceram quase todos inéditos à época, foram publicados pela primeira vez no primeiro tomo dos "Anales del Museo Nacional de Montevideo", com uma introdução de Carlos M. de Pena (Pena, 1897), e no início dos anos 1920, em uma homenagem do Instituto Histórico e Geográfico do Uruguai.

Larrañaga, que era hábil desenhista e ilustrava seus próprios textos, ainda que se reconhecesse como discípulo fiel de Lineu, utilizava para classificação dos fósseis sistemas que se diferenciavam do lineano pelas reformas de Blumembach e Cuvier. Como seus contemporâneos europeus, ou do Prata, e tantos outros, Larrañaga também propunha suas próprias classificações e adaptava as diversas existentes para o reino animal, especialmente sul-americano. No primeiro volume de seus "Diários de Historia Natural", iniciados em $1^{\circ}$. de janeiro de 1808 e finalizados em abril de 1813, contendo cerca de 2.000 descrições e classificações, Larrañaga adaptou Lineu, classificando os animais seguindo os embranchements de Cuvier: os vertebrados (peixes, aves, répteis e mamíferos), os moluscos, os articulados (insetos, aracnídeos, crustáceos e anelídeos) e os radiados. Mencionando autores e obras e evidenciando sua erudição e acesso à bibliografia atualizada, seguia Lamarck (sistema de 1778, versão de 1786, segundo suas citações) em sua flora da França, mas também se servia dos trabalhos gerais para as espécies que não se encontravam em Gmelin (Podgorny e Lopes, 2008). No segundo volume desses "Diários", há também descrições do território Oriental, costumes dos habitantes e comentários práticos sobre agricultura.

Para sua "Memoria geológica sobre la reciente formación del Río de la Plata, deducida de sus conchas fósiles",
Larrañaga recorria à nova ciência da Geologia como o único e mais garantido meio para desvendar os tempos obscuros da história do país. Como os antepassados não haviam deixado vestígios de suas civilizações, como no território paulista de José Bonifácio, a história da região não ia muito além de três séculos. E, antes de recorrer a fábulas, com mais proveito e dignidade recomendava consultar a natureza. Lamentando que 'desgraçadamente' os principais objetos de estudo da geologia ainda estavam ocultos aos olhos, no seu país, confessava que em seus primeiros anos de estudo havia se deixado levar pela mania do século de colecionar conchas. Justificava sua dedicação ao estudo das conchas fósseis dos arredores de Montevidéu, uma vez que não havia "una mina abierta ni una roca. Me vi, pues, precisando a fijar mi atención sobre varios depósitos de conchas fósiles de los contornos de esa capital; y véase aquí el resultado de mi investigaciones" (Larrañaga, 1923a, p. 22-28).

Seguindo Lineu para a classificação das conchas, de posse de bibliografia internacional especializada para suas classificações, Larrañaga admitia a perda de prioridade, mesmo que não concordasse totalmente. Enquanto se dedicava à classificação de conchas que considerava novas para o sistema de Lineu, atualizou-se sobre uma memória de Malton de 1809, lida na Sociedade Lineana de Londres, descrevendo sete espécies de conchas e caracóis. Uma bivalva não deveria

\begin{abstract}
de ningun modo colocarse entre las Myas, despues de las desmembraciones que ha padecido este género. En esta familia establecida por Cuvier solo deben colocarse aquellas bivalvas que a más de otros caracteres tengam sus extremos más o menos entreabiertos; y según confesión del Sr. Maton valvae sunt ochissima... Creo, pues, que debe hacerse un nuevo género: Matonia antigua (Larrañaga, 1923b, p. 8).
\end{abstract}

Em seguida, o autor passa a descrever o animal em latim, mas a prioridade coube a D'Orbigny4.

\footnotetext{
4 Embora os primeiros artigos publicados sobre os depósitos fossilíferos marinhos do Quaternário no Uruguai sejam os de d'Orbigny, de 1842, as primeiras menções às camadas de conchas e classificações se devem aos trabalhos de Larrañaga, do início do século XIX (Martínez et al., 2006).
}

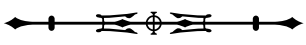


Conchas foram a base segura de suas teorias geognósticas sobre a formação recente do Rio de la Plata. Aceitava, como os geólogos, inundações parciais em terrenos específicos, que se distinguiam por sua composição, como as "11 formações parciais e as mais de 70 camadas" que se alternavam por suas deposições marinhas e fluviais mapeadas nos trabalhos estratigráficos clássicos de Cuvier e Brogniart nos arredores de Paris. Mas não considerava necessárias tão repetidas revoluções e grandes catástrofes, como queriam Cuvier e Brogniart, para explicar as formações conchiliferas do entorno de Montevidéu, que mesclavam produções marinhas e fluviais. Colocando-se as questões em debate à época, sobre a uniformidade, velocidade e intensidade de processos geológicos na história da Terra, perguntava:

De un modo igualmente sencillo y aun más natural podemos explicar la formación de estas camadas de conchilla marina que se encuentra en nuestro país en las riberas de este gran Rio. Yo pudiera recurrir a esa causa lenta, silenciosa y general que hace retirar los mares de ciertas costas y avanzar sobre otras. Yo pudiera preguntar si esa misma causa que con tanta lentitud obra sobre la precesión de los equinoxios no podría obrar sobre la situación de los mares? Yo pudiera preguntar si conocemos bien cuál o cuantos son los agentes que causan las mareas, y si estos no tuvieron en otro tiempo mayor actividad? (Larrañaga, 1923b, p. 11).

Que o mar havia coberto toda a superfície da Terra a um mesmo tempo, segundo afirmava o relato bíblico, já não se podia negar, como escreveu Larrañaga em uma de suas memórias sobre a "Piedra de cal de Buenos Aires" (Larrañaga, 1923a, p. 22). Lembrando que tanto Ulhoa como Humboldt encontraram conchas fósseis nas elevadas altitudes da América, não deixava de escarnecer da descrença de Voltaire, que negava a existência dessas conchas no alto das montanhas, no sentido moderno de fósseis. Além dessas considerações para dissertar sobre a formação dos depósitos de conchas fluviais, marinhas e 'semimarinhas' que se alternavam no entorno de Montevidéu, remetia à sequência das camadas contendo 'belemnites, nummulites, etc.' com que Cuvier estabelecia a existência de grandes lagos para explicar a formação dos depósitos conchilíferos de água doce. E em reforço à crença na cronologia bíblica, criticava os "filósofos superficiais":

Los salvan, desde luego, toda dificultad recurriendo a grandes y repetidas revoluciones generales en el globo; y quieren para esto dar a la tierra una antigüedad que no han encontrado los grandes maestros en esta ciencia. Yo soy de opinión, dice Cuvier (Ensayo sobre la teoría de latierra, p. 34) con Mr. Delucy M. Dolomieu, que la época de una grande y repentina revolución de nuestro globo, no puede datarse más allá de cinco a seis mil años. Mientras yo, pues, no advierta más depósitos que los que apareen sobre las riberas del Rio, y de una naturaleza aluvial de las más modernas, no creo necesario recurrir a otros agentes para dejarlos en seco y fuera del mar (Larrañaga, 1923b, p. 13).

De um "modo simples e natural" passava a explicar "la formación de estas camadas de conchilla marina que se encuentra en nuestro país en las riberas de este gran Rio" (Larrañaga, 1923b, p. 13).

De qualquer modo que se explicasse a formação estratigráfica de tais depósitos, Larrañaga estava convicto de que sempre seria necessário fazer desaparecer o Rio de la Plata e fazê-lo posterior a essas formações. Os terrenos ocupados pelo rio teriam sido primeiramente ocupados pelo mar e a existência do Guazú seria mais moderna que a do Paraná, até cuja embocadura pelo menos chegava o mar.

Sua preciosa e minuciosa dissertação sobre a história geológica da região iniciava com as rochas "primordiais" dos geólogos: os gnaisses na base de Montevidéu; granitos no interior e diabásio sustentando as serranias, embora afirmasse que "el sabio naturalista prusiano Mr. Sellow ha confirmado mis ideas y no ha podido encontrar hasta hora roca ninguna con cuerpos organizados ni vestigio alguno volcánico. Igual observación ha hecho en el Brasil" (Larrañaga, 1923b, p. 14).

As três únicas formações que encontrara lhe pareciam todas "de un origen no muy antiguo en los principios geológicos”. A primeira formação era de um grés calcário, composto de grãos de quartzo arredondados, alguns brilhantes e outros um tanto arroxeados e transparentes, com proporções iguais de 
fragmentos de conchas de difícil determinação. A segunda formação era dos Mytilos ou Megillones do entorno de Montevidéu, seguindo pela costa para Maldonado. E a terceira, das Myas, que ao final de diversas observações lhe pareceram "haber internádose en el actual Guazú" em época mais recente. Tão características eram essas conchas nas respectivas formações que nunca encontrou uma só Mya na formação dos Mytilos, nem um Mytilo na formação das Myas, sendo que as demais conchas eram comuns às duas formações em maiores ou menores quantidades. Os depósitos entre o Cerro e o rio de Santa Lúcia, formados de delicados Mytilos que não sobrevivem em água doce, lhe permitiam teorizar sobre o avanço do rio para o oceano e como o rio, com tempo, também se modificara, "nada más natural que a más de sus depósitos aluviais, que con o tempo ha formado como unos grandes diques contra el océano, haya aumentado sus aguas" (Larrañaga, 1923b, p. 16). Imaginando longos períodos de alternância entre as regressões e transgressões marinhas e comparando os combates entre rio e mar àqueles das guerras políticas, em que são os habitantes os que mais sofrem, explicava o acúmulo das conchas nas rochas, características desses processos de deposições sedimentares. Admitindo que a sequência estratigráfica pudesse estar sujeita a modificações frente a novos estudos, afirmava não ter "duda alguna sobre la naturaleza marítima de todos estos depósitos de conchas fósiles ni tampoco debe haberla sobre las tres diferentes formaciones en tres diferentes épocas" (Larrañaga, 1923b, p. 19).

Explica, ainda, quanto aos depósitos de aluvião da região, que estes eram mais recentes. Eram de 'orden terciario' e ainda da última série das formações dessa ordem. E para concluir a "Memória geológica", resume seu discurso em poucas palavras: "La formación del Rio de la Plata es reciente: él es el autor de estos depósitos y los há hecho con sus proprios materiales. A este terreno de aluvión y aun más reciente pertenece nuestro Megatherio" (Larrañaga, 1923b, p. 20).

Na já mencionada memória sobre a "Piedra de cal de Buenos Aires por un hijo del país", na qual estabelece correlações entre as camadas conchilíferas das duas margens escavadas pelo Prata, retoma suas classificações e dúvidas significativas, para aconselhar o estudo da natureza - "libro siempre abierto, tan veraz, como interesante" - aos jovens, não só porque aí encontrariam um "prazer mui puro" como também porque assim "contribuirán en grande manera a la glória y felicidad de nuestro país" (Larrañaga, 1923a, p. 21 e 24).

\section{CONSTRUTORES DE UMA GEOHISTÓRIA DA NATUREZA}

José Bonifácio (mineralogista), Hipólito Unanúe (médico) e Dámaso Larrañaga (padre) tiveram em comum suas atuações ilustradas que não dissociavam política e ciência. Seus discursos não se referiam mais a interpretações puramente retóricas ou qualitativas sobre uma 'natureza' vaga, inacessível. Suas naturezas estavam a serviço de civilizações. Estavam sendo postas sob controle: fosse uma bela paisagem a ser explorada economicamente, vales e montanhas cuja força de seus tremores deveria ser medida, ou antigos rios e mares que mereciam ser mapeados. Contribuíram com suas práticas e memórias de forma ativa para a construção do conhecimento científico na e da América, de forma não dissociada de sua atuação política igualmente destacada. Em comum, partilhariam polêmicas historiográficas acerca de seus compromissos político-revolucionários: o 'português D'Andrada' não teria sido um promotor de primeira hora da independência do Brasil; Unanúe também não fora um súdito rebelde. Colaboracionista ou estrategista, reivindicado pelos argentinos ${ }^{5}$, imortalizado por Cuvier como brasileiro, sem ter sido incorporado pela historiografia nacional, a

\footnotetext{
5 Dada sua destacada atuação em Buenos Aires e em Montevidéu antes da independência uruguaia das Províncias Unidas del Rio de la Plata, autores argentinos, como Guillermo Furlong, incluíram Larrañaga entre os naturalistas argentinos durante a ocupação hispânica, embora continuasse a se referir a ele como sábio oriental (Favaro, 1950).
}

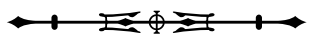


trajetória de Larrañaga evidencia que as fronteiras entre os países do sul da América foram mais móveis do que costumamos lembrar.

Esses pequenos trechos dos escritos de Bonifácio, Unanúe e Larrañaga nos deixam ver como esses ilustrados praticavam suas ciências em territórios não europeus, sem absolutamente se sentirem não participantes da construção do conhecimento. Partilharam a crença em prodigalidades específicas da natureza americana, que, acima de tudo, investigaram de maneira original. A utilidade da natureza pródiga em recursos minerais para São Paulo, revigorada pelos tremores em Lima ou aberta aos estudos mesmo através de pequeninas conchas no rio de la Plata - é apenas um indício que nos deixaram das construções sobre a geohistória (Rudwick, 2008) da América que se tornaria Latina. Nos quadros otimistas característicos do período, onde o povo ainda não era rico e culto, o potencial da natureza se tornaria a principal fonte de riqueza e civilização; onde já existia cultura e riqueza, era a força e a regularidade dos tremores que garantiria o bem estar da civilização no clima ameno; onde faltavam monumentos das antigas civilizações, era a "Geologia, esta nueva ciencia que se remonta más allá de todas las historias profanas, y com cuyas luces en muy pocos años se han hecho descubrimientos los más interesantes" (Larrañaga, 1923a, p. 21) que traria glória e felicidade aos povos.

Engajados nos projetos político-reformistas ilustrados, seja de modernização do Império português ou espanhol ou de sobrevivência de seus novos países, as ciências lhes forneceram referenciais metodológicos para interpretarem a natureza, mapearem possíveis novas fontes de recursos econômicos, entenderem o temperamento de suas regiões para assegurarem as condições de vida de suas gentes ou simplesmente traçarem as trajetórias de antigos mares e rios.

\section{REFERÊNCIAS}

ACHIM, Miruna. La querella por el temperamento de México. Meteorología, Hipocratismo y Reformas Urbanas a finales del siglo XVIII. In: GORBACH, Frida; LÓPEZ BELTRÁN, Carlos (Eds.). Saberes locales: ensayos sobre historia de la ciencia en América Latina. México: El Colegio de Michoacán, 2008. p. 235-261.
ARREGUI, Federico Álvarez. El debate del Nuevo Mundo. In: PIZARRO, Ana (Org.). América Latina: palavra, literatura e cultura. Emancipação do discurso. São Paulo: Memorial; Campinas: Unicamp, 1994. v. 2, p. 35-66.

BORK, Kennard B. Elie Bertrand (1713-1797) sees God's order in Nature's record: the 1766 'Recueil de divers Traits sur l'Histoire Naturelle'. Earth Science History, v. 10, n. 1, p. 73-88, 1991.

CAÑIZARES-ESGUERRA, Jorge. Nation and nature: natural history and the fashioning of creole national identity in late colonial Spanish America. In: CONGRESSO INTERNACIONAL LATIN AMERICAN STUDIES ASSOCIATION, 20., 1997, Guadalajara. Anais... Guadalajara: LASA, 1997. Mimeografado.

CARDOSO, José Luis. Nas malhas do Império: a economia política e a política colonial de D. Rodrigo de Sousa Coutinho. In: CARDOSO, José Luis (Org.). A economia política e os dilemas do Império luso-brasileiro (1790-1822). Lisboa: Comissão Nacional Para as Comemorações dos Descobrimentos Portugueses, 2001. p. 28-52.

CAROZZI, Marguerite. Reaction of British Colonies in America to the 1755 Lisbon Earthquake - a comparison to the European response. Earth Science History, v. 2, n. 1, p. 17-27, 1983.

CASALINO, Carlota. Hipólito Unanúe: el poder político, la ciencia ilustrada y la salud ambiental. Revista Peruana de Medicina Experimental, v. 25, n. 4, p. 16-29, oct.-dic. 2008.

CUVIER, Georges. Recherches sur les Ossemens Fossiles oú l'on rétablit. Les caractères de plusiers animaux dont les révolutions du globe ont détruit les espéces. Nouvelle Édition entièrement refondue, et considérablement augmentée. Tome cinquième, Ier. Partie, contenant les rongeurs, les édentés, et les mammifères marins. Paris: chez G. Dufour et E. D'Ocagne Libraires, et a Amestardam, chez les mémes, 1823.

FAVARO, Edmundo. Dámaso Antonio Larrañaga. Su vida y su época. Montevideo: Impressora Rex S.A., 1950.

FONSECA, Maria Rachel F. “A única Ciência é a Pátria”: o discurso científico na construção do Brasil e do México (1770-1815). 1997. Tese (Doutorado em História Social) - Universidade de São Paulo, São Paulo, 1997.

FONSECA, Maria Rachel F. Ciência e Identidade na América Espanhola (1780-1830). In: GEBRAN, Philomena; LEMOS, Maria Teresa Brittes (Orgs.). América Latina: Cultura, Estado e Sociedade. Novas Perspectivas. Rio de Janeiro: ANPHLAC, 1994. p. $131-154$

GERBI, Antonello. O Novo Mundo. História de uma Polêmica (1750-1900). São Paulo: Cia. das Letras, 1996.

GLICK, Thomas F. Science and Independence in Latin América (with special reference to New Granada). Hispanic American Historical Review, v. 71, n. 2, p. 307-334, 1991.

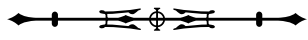


GONZÁLES, Ariosto D. Prologo. In: FAVARO, Edmundo Damaso. Antonio Larrañaga. Su vida y su época. Montevideo: Impressora Rex S.A., 1950. p. VII-XIII.

KOK, Glória. O sertão itinerante: expedições da capitania de São Paulo no século XVIII. São Paulo: HUCITEC; FAPESP, 2004. (Coleção Estudos Históricos).

LARRAÑAGA, Dámaso A. Oracion inaugural. Biblioteca de Montevideo. In: LARRAÑAGA, Dámaso A. Escritos de D. Dámaso Antonio Larrañaga. Instituto Histórico y Geográfico del Uruguay. Edición Nacional. Montevideo: Imprenta Nacional, 1924. Tomo III, p. 136-146.

LARRAÑAGA, Dámaso A. Memoria geológica sobre la Piedra de cal de Bs. As. Por un hijo del país. In: LARRAÑAGA, Dámaso A. Escritos de Don Dámaso Antonio Larrañaga. Instituto Histórico y Geográfico del Uruguay. Edición Nacional. Montevideo: Imprenta Nacional, 1923a. Tomo III, p. 22-28.

LARRAÑAGA, Dámaso A. Memoria geológica sobre la reciente formación del Río de la Plata, deducida de sus conchas fósiles. In: LARRAÑAGA, Dámaso A. Escritos de D. Dámaso Antonio Larrañaga. Instituto Histórico y Geográfico del Uruguay. Edición Nacional. Montevideo: Imprenta Nacional, 1923b. Tomo III, p. 7-20.

LOPES, Maria Margaret. José Bonifácio de Andrada e Silva - o Mineralogista - na produção historiográfica brasileira. Quipu, v. 7, n. 3, p. 335-344, set.-dez. 1990

LOPES, Maria Margaret; PODGORNY, Irina. The shaping of Latin American museums of natural history, 1850-1990. Osiris, n. 15, p. $108-118,2000$

LYRA, Maria de Lourdes Viana. A utopia do poderoso Império. Portugal e Brasil: Bastidores da Política. Rio de Janeiro: Sette Letras, 1994.

MARTíNEZ, Sergio; ROJAS, Alejandra; UBILLA, Martín; PEREA, Daniel; PIÑEIRO, Graciela. Molluscan assemblages from the marine Holocene of Uruguay: composition, geochronology, and paleoenvironmental signals. Ameghiniana, v. 43, n. 2, p. $385-$ 397, 2006

MUNTEAL FILHO, Oswaldo. Uma sinfonia para o novo mundo: a Academia Real das Ciências de Lisboa e os caminhos da llustração luso-brasileira na crise do antigo sistema colonial. 1998. Tese (Doutorado em História) - Universidade Federal do Rio de Janeiro, Rio de Janeiro, 1998.

MUNTEAL FILHO, Oswaldo. Domenico Vandelli no anfiteatro da natureza: a cultura científica do reformismo ilustrado português na crise do antigo sistema colonial (1779-1808). 1993. Dissertação (Mestrado em História) - Pontifícia Universidade Católica, Rio de Janeiro, 1993.

NAXARA, Márcia Regina Capelari. Natureza e Civilização: sensibilidades românticas em representações do Brasil no Século XIX. In: BRESCIANI, Stella; NAXARA, Márcia (Orgs.). Memória e (Res)sentimento: indagações sobre uma questão sensível. 2. ed. Campinas: Editora da Unicamp, 2009. v. 1, p. 431-455.
OLDROYD, David; AMADOR, Filomena; KOZAK, Jan; CARNEIRO, Ana; PINTO, Manuel. The study of earthquakes in the hundred years following the Lisbon earthquake of 1755. Earth Science History, v. 26, n. 2, p. 321-370, 2007.

PENA, Carlos Maria de. Introducción. In: LARRAÑAGA, Dámaso A. Memoria geológica sobre la formación del Río de la Plata, deducida de sus conchas fósiles, escrita por los años 1819. Anales del Museo Nacional de Montevideo, Tomo I, p. 7-47, 1897.

PODGORNY, Irina. De ángeles, gigantes y megatérios. El intercambio de fósiles de las provincias del Plata en la primera mitad del siglo XIX. In: SALVATORE, Ricardo (Org.). Los lugares del saber. Contextos locales y redes transnacionales en la formación del conocimiento moderno. Rosario: Beatriz Viterbo Editora, 2007. p. 125-157.

PODGORNY, Irina; LOPES, Maria Margaret. El Desierto en una vitrina. Museos e historial natural en la Argentina, 1810-1890. 1. ed. México: LIMUSA, 2008.

PORRAS BARRENECHEA, Raul. Ideólogos de la Emancipacón. Lima: Editorial Milla Batres, 1974.

RUDWICK, Martin. Worlds before Adam: the reconstruction of geohistory in the age of reform. Chicago: The Chicago University Press, 2008.

SAINT-HILAIRE, Auguste A. Viagem ao Rio Grande do Sul (18201821). Tradução A M. da Costa. Brasília: Senado Federal, 2002.

SALADINO GARCÍA, Alberto. Ciencia y prensa durante la ilustración latinoamericana. México: Universidad Autónoma del Estado de México, 1996.

SALAVERRY, Oswaldo. Los orígenes del pensamiento médico de Hipólito Unanúe. Anales de la Facultad de Medicina, v. 66, n. 4 , p. 357-370, 2005

SILVA, Clarete Paranhos. Garimpando memórias: as ciências mineralógicas e geológicas no Brasil na transição do século XVIII para o XIX. 2004. Tese (Doutorado em Geociências) Universidade de Campinas, Campinas, 2004.

SILVA, José Bonifácio de Andrada e; ANDRADA, Martim Francisco Ribeiro de. Viagem Mineralógica na Província de São Paulo (1820). In: FALCÃO, Edgard Cerqueira (Org.). Obras Científicas, Políticas e Sociais de José Bonifácio de Andrada e Silva. Santos: Revista dos Tribunais, 1963. p. 220-268.

UNANÚE, José Hipólito. Observaciones sobre el clima de Lima y sus influencias en los seres organizados en especial el hombre (1806). In: Obras científicas y Literarias de José Hipólito Unanúe. Lima: Editorial Universo, 1975. Tomo Primeiro.

VARELA, Alex Gonçalves. Atividades Científicas na "Bela e Bárbara” Capitania de São Paulo (1796-1823). São Paulo: Annablume, 2009.

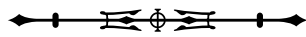


VARELA, Alex Gonçalves. Naturalistas e homens públicos: a trajetória dos ilustrados Hipólito Unanúe e José Bonifácio Andrada e Silva. In: ENCONTRO INTERNACIONAL DA ANPHLAC, 7., 2006, Campinas. Anais eletrônicos... Campinas: ANPHLAC, 2006a. Disponível em: <http://www.anphlac.org/periodicos/anais/ encontro7/alex_varela.pdf >. Acesso em: 21 jun. 2010.

VARELA, Alex Gonçalves. "Juro-lhe Pela Honra de Bom Vassalo e Bom Português”: Análise das memórias científicas de José Bonifácio de Andrada e Silva (1780-1819). São Paulo: Annablume, 2006b.
VARELA, Alex Gonçalves; LOPES, Maria Margaret. As atividades científicas do naturalista Martim Francisco Ribeiro de Andrada na capitania de São Paulo (1800-1805). História, Ciências, Saúde Manguinhos, v. 14, n. 3, p. 947-972, jul.-set. 2007.

Recebido: 16/01/2010

Aprovado: 21/06/2010 